\title{
Immunohistochemical studies show truncated dystrophins in the myotubes of three fetuses at risk for Duchenne muscular dystrophy
}

Ieke B Ginjaar, Egbert Bakker, Marleen M B van Paassen, Johan T den Dunnen, Andy Wessels, Elizabeth E Zubrzycka-Gaarn, Antoon F M Moorman, Gert-Jan B van Ommen

\begin{abstract}
We have performed immunohistochemical studies on muscle tissue of three 12 week old fetuses at risk for DMD, using antisera directed against regions located NH2-proximally and centrally in the rod shaped spectrin-like domain and against the COOH-terminus of dystrophin. All three fetuses had a family history of DMD. Truncated dystrophins were identified in all three cases by a positive reaction with the NH2-proximal antibody, different reactions with the central antibody, and a negative reaction with the $\mathrm{COOH}$-terminal antibody. These data indicate that a panel of antibodies would, in principle, permit 'immunological' mapping of dystrophin mutations. This is diagnostically important in the $35 \%$ of families where no mutation is detectable at the DNA level. Secondly, by using this mapping technique it may also become possible to identify the at risk haplotype when DNA analysis is not informative. This may be of great value in DMD carrier detection.
\end{abstract}

$\mathrm{X}$ linked Duchenne muscular dystrophy (DMD) is the most common of all severe muscular dystrophies

Department of Human Genetics, Sylvius Laboratory, Wassenaarseweg 72, 2333 AL Leiden, The Netherlands.

I B Ginjaar, E Bakker, M B M van Paassen, J T den Dunnen, G-J B van Ommen

Department of Anatomy and Embryology, AMC, $1105 \mathrm{AZ}$ Amsterdam, The Netherlands.

I B Ginjaar, A Wessels, A F M Moorman

Hospital for Sick Children, Toronto, Canada. E E Zubrzycka-Gaarn

Correspondence to Dr van Ommen.

Received for publication 19 September 1990.

Revised version accepted for publication 1 February 1991.
( 1 in 3500 live male births) progressing to death in early adulthood. The milder Becker muscular dystrophy (BMD) has a later age of onset, but is caused by mutations in the same gene. DNA technology has allowed reliable diagnosis with more than $99 \%$ certainty in most familial DMD cases. ${ }^{1-5}$ Dystrophin, ${ }^{6}$ the DMD gene product, has been localised in the sarcolemma of the muscle cell. ${ }^{7-10}$ In muscle biopsies of Duchenne patients no dystrophin can be detected, whereas in BMD patients dystrophin of abnormal size or quantity is observed. ${ }^{7811}$ The combined results of protein and DNA studies ${ }^{4}{ }^{12-15}$ have confirmed the hypothesis ${ }^{16}$ that the Duchenne phenotype might be caused by an 'out of frame' mutation of the gene, although some exceptions have been found. The mutations produce a prematurely terminated protein, which is apparently unstable and thus degraded. Similarly, BMD is caused by 'in frame' mutations, resulting in a partly functional protein of altered molecular weight. In a preliminary study of muscle tissue of a fetus at risk for DMD, truncated dystrophin was detected immunohistochemically. ${ }^{17}$ The presence of abnormal dystrophin early in development indicates that its degradation takes place at a later stage. We describe here the presence of truncated dystrophins in two more fetuses at risk for DMD using antisera raised against three different regions of dystrophin and discuss the implications for fetal dystrophin analysis and the pinpointing of undetectable DMD mutations.

Materials and methods PRENATAL DIAGNOSIS

Case 1 (fig 1A)

The proband (5) is a carrier and two of her brothers died of DMD at the ages of 14 and 19 years. A brother of the grandmother (carrier) also died very young. 
The proband decided to terminate the male pregnancy after haplotyping had indicated a $>99 \%$ risk of an affected fetus. DNA analysis of this mother indicated a duplication in the central part of the gene. ${ }^{14} 17$
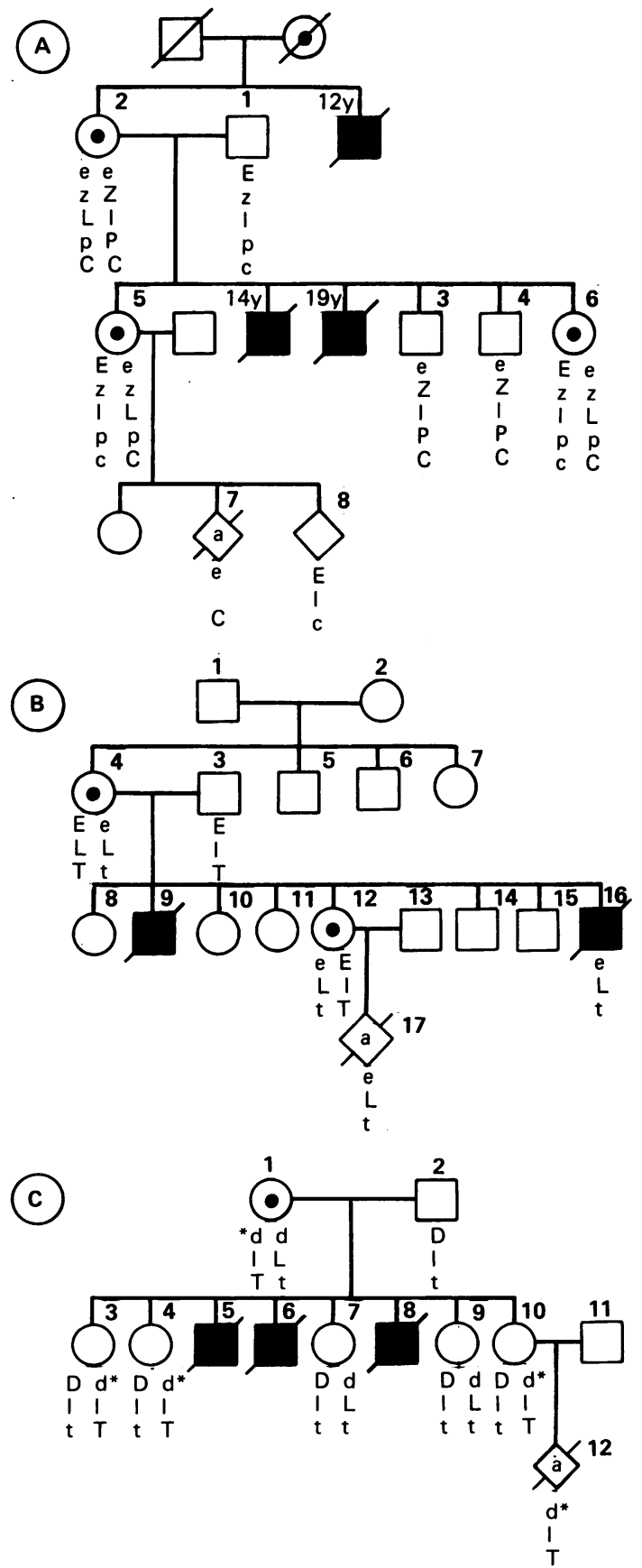

Case 2 (fig 1B)

The proband (12) had two brothers affected with DMD. The proband had a $>99 \%$ carrier risk. No DNA abnormality could be detected in this family. After prenatal diagnosis had indicated the presence of a male fetus carrying the at risk haplotype, the parents decided to terminate the pregnancy.

Case 3 (fig 1C)

Three brothers of the proband (10) died of DMD. No mutation could be found in the DMD gene. Moreover, as rarely occurs, none of the available DNA markers was informative in the carrier grandmother (1), so the proband's carrier risk remained unaltered at $50 \%$. The only informative marker in the proband herself was the distal marker 782 (DXS85), ${ }^{19}$ located about $20 \mathrm{cM}$ distally. Therefore, the reliability of the DNA test, to discriminate between a grandpaternal and grandmaternal $\mathrm{X}$ chromosome, would not exceed $80 \%$. Since the grandmaternal $50 \%$ at risk $X$ chromosome was detected in the male fetus (12), the prospective parents elected to terminate the pregnancy.

\section{DNA ANALYSIS}

DNA was isolated from whole blood or chorionic villus samples; restriction enzyme digestions and blot hybridisations were as described by Bakker et al. ${ }^{2}$ Restriction endonucleases were purchased from Pharmacia.

IMMUNOHISTOCHEMICAL ANALYSIS

The at risk fetuses were aborted by aspiration in the 12th week of pregnancy. Normal fetuses were obtained similarly after legal abortion for non-pathological reasons. Limited tissue material was available for the at risk fetuses. Intact leg segments of fetuses 2 and 3 and the controls were fixed for one to three days at room temperature in a mixture of methanol, acetone,

Figure 1 (A) Pedigree of family 1 segregating DMD. For carrier detection in this family the flanking probes $p D 2^{18}$ $(D X S 164)(E)$ and $754^{19}(D X S 84)(C)$, the intragenic genomic probes $p 87 \cdot 15(L)$ and $p 87 \cdot I(P)(D X S 164),{ }^{20}$ and $5 b-7 / c D N A$ probe ${ }^{3}(Z)$ were used. Daughters 5 and 6 have inherited the at risk chromosomes $e-z-L-p-C$. Prenatal diagnosis (7) was performed according to Bakker et $a^{2}$ by using the flanking markers pD2 and 754. (B) Pedigree of DMD family 2, For carrier detection and prenatal diagnosis the markers $p D 2(E)$, p87-15 $(L)$, and 754-11(T) ${ }^{21}$ were used. Daughter 12 and fetus 17 have inherited the at risk chromosome e-L-t. (C) Pedigree of family 3 . For carrier detection and prenatal diagnosis the only informative marker was $782(D)$. The fetus (12) has inherited one of the grandmaternal $X$ chromosomes $d$; the chance of this fetus being affected with DMD is $50 \%$. To discriminate between the two maternal haplotypes genomic probes p87-15(L) and 754 $(T)$ are indicated in the pedigree. 
acetic acid, and water (35:35:5:25 by vol) followed by dehydration in acidified 2.2.dimethoxypropane (Merck) and embedding in paraplast ${ }^{22}$ (Monoject). Because the DMD fetus of family 1 arrived frozen in liquid nitrogen, the tissue was freeze substituted for seven days at $-40^{\circ} \mathrm{C}$, in the same methanol/acetone/ acetic acid/water mixture, dehydrated, and embedded in paraplast. For immunohistochemical staining, $7 \mu \mathrm{m}$ thick sections of the legs of normal and DMD fetuses were deparaffinated and immunostained as described by Moorman et al. ${ }^{23}$ All the sera were diluted in PBS. The polyclonal antibodies used for incubations were affinity purified rabbit polyclonal antibodies, directed, respectively, against a $30 \mathrm{kd}$ subpeptide consisting of amino acid $1181-1388^{24}$ (30 $\mathrm{kd} A B$, fusion protein obtained from $\mathrm{E}$ Hoffman and antibody raised by KHF), a $59 \mathrm{kd}$ subpeptide made of cDNA $^{3} 5.5$ to $7.0 \mathrm{~kb}$, corresponding to amino acids 1750-2248, named P20-AB after the origin from the P20 deletion prone region, ${ }^{25}$ and against a peptide containing the last 17 amino acids, 3669-3685, of dystrophin (1460 AB, raised by EEZ-G).

\section{Results}

In the carrier female of family 1 an intragenic duplication was detected ${ }^{14}{ }^{17}$ (fig 2). Families 2 and 3, however, belong to the $35 \%$ of families without detectable mutations in the DMD gene. Given the severity of the disease in all three families, the mutation in the gene probably results in a frameshift producing a truncated dystrophin. We performed immunohistochemical studies on muscle tissue of 12 week old fetuses, using three different polyclonal antibodies, directed against a $\mathrm{NH}_{2}$-proximal segment (30 kd AB), a central segment (P20 AB), and the $\mathrm{COOH}$-terminus (1460 AB) respectively (see Materials and methods). Fig 3 shows a control experiment to show the specificity of the central P20 antibody, with normal, mature muscle staining positively (A), with that of a female, manifesting DMD carrier (B) staining in a clear mosaic fashion, ${ }^{27}$ and with that of a DMD patient $(C)$ showing absence of signal. Our parallel studies have shown that at 12 weeks of development dystrophin is not yet fully membrane associated, but is just beginning to appear

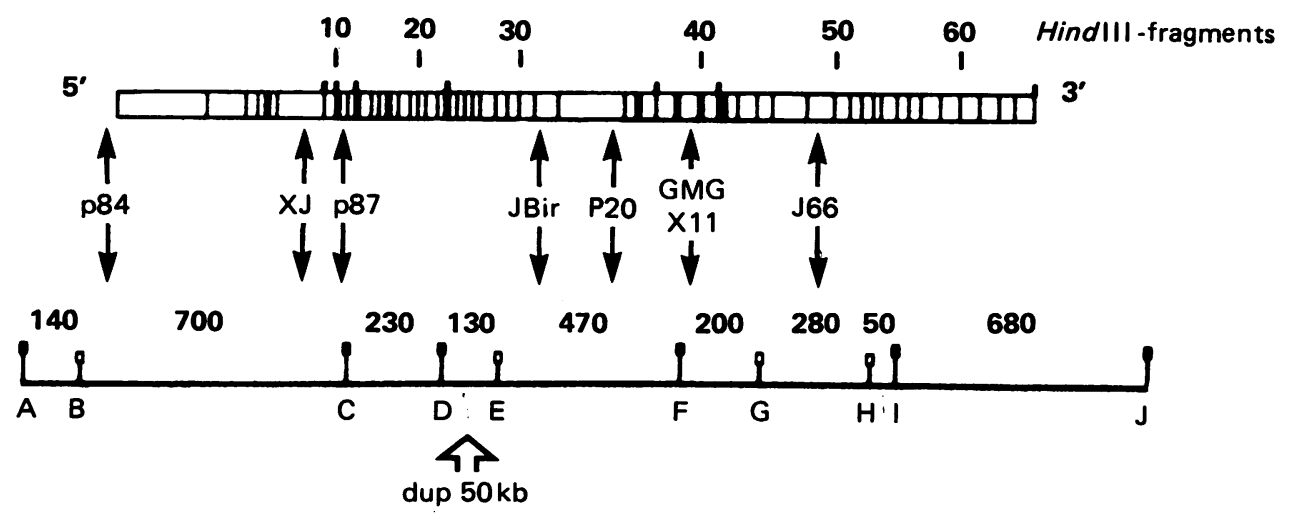

Figure 2 A Sfil physical map in the DMD region. ${ }^{26}$ Fully and partially digestible SfiI sites are represented by closed and open boxes, respectively. The SfII fragment lengths are written in $k b$ above the map, as are the locations of the genomic probes. Above the figure 65 genomic HindIII fragments are drawn, most of which correspond to only one exon. The DNA duplication in family 1 is situated in $D E$.

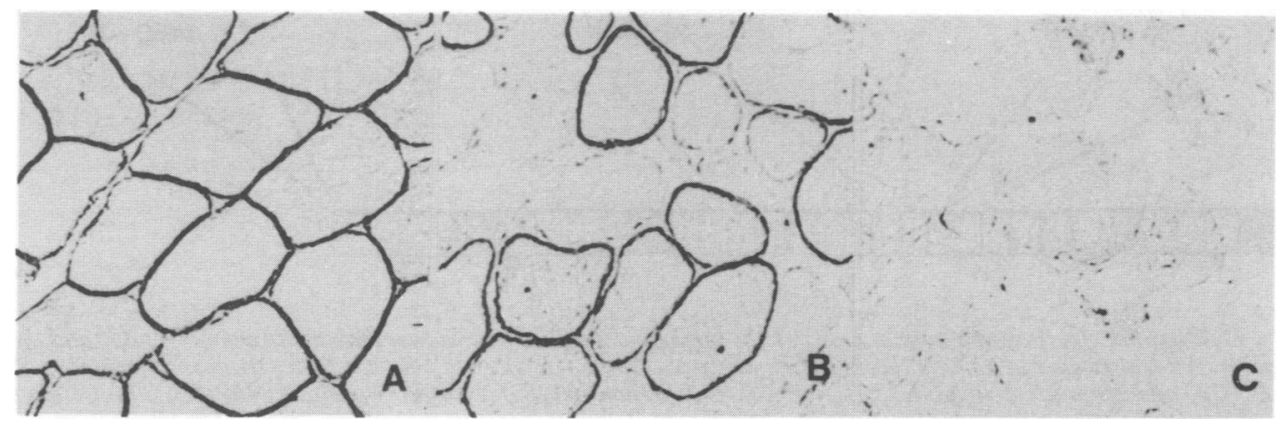

Figure 3 (A) Normal muscle tissue (m quadriceps) incubated with $P 20,(B)$ muscle tissue from a female $D M D$ carrier, and $(C)$ muscle tissue from a DMD patient incubated with P2O antiserum. 

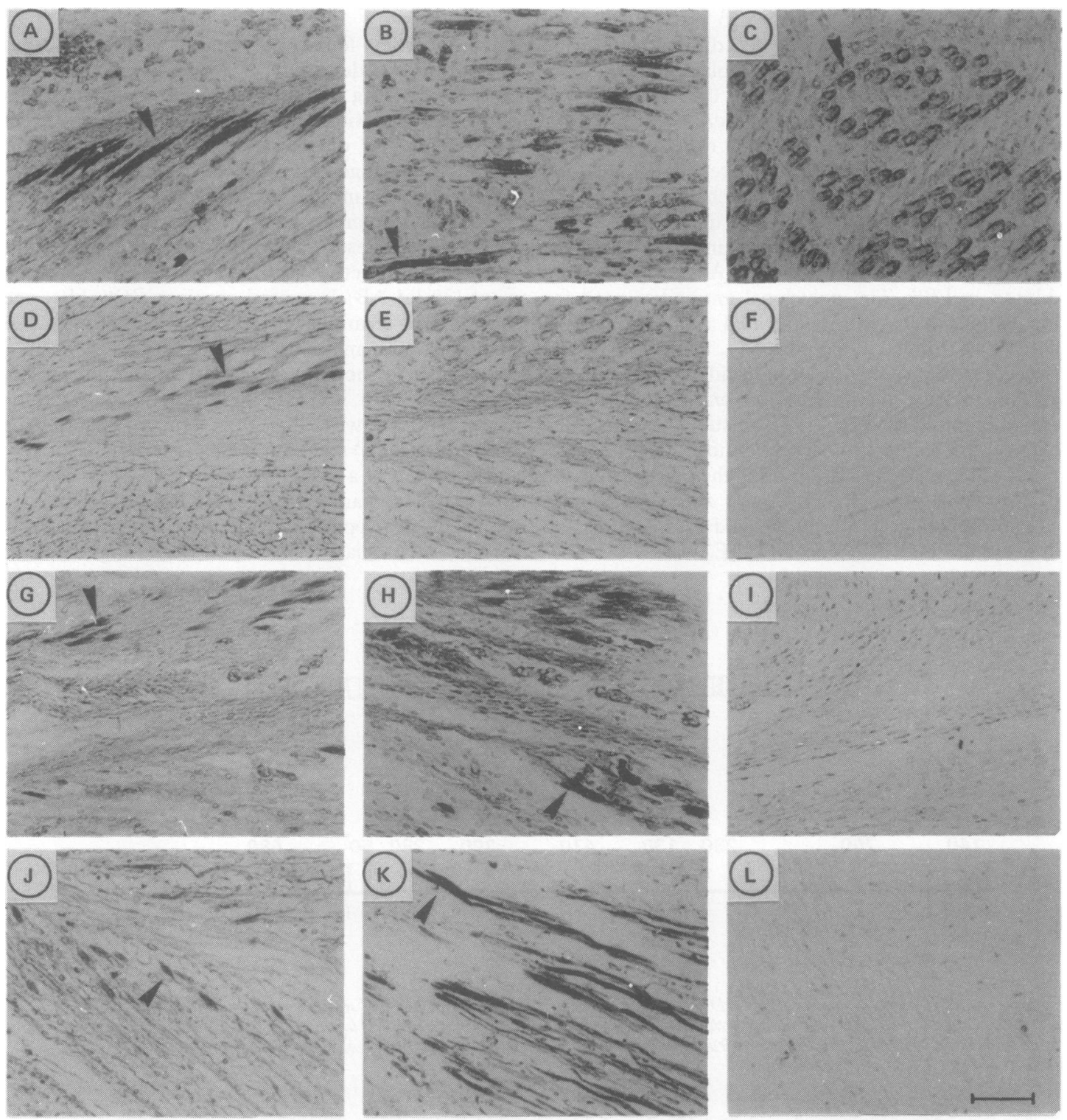

P20 AB

$1460 \mathrm{AB}$
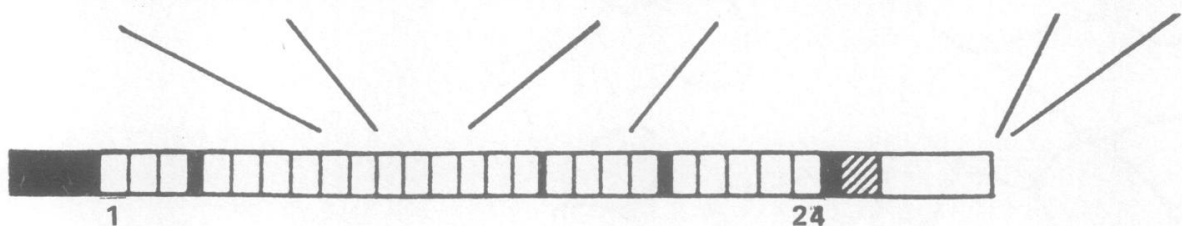

Figure 4 Dystrophin expression in a normal human fetus (many independent fetuses were tested with similar results) and three $D M D$ fetuses. All fetuses were at about 12 weeks of development. Sagittal sections of fetal muscle leg tissue incubated with $(A, D, G, \mathcal{Y})$ affinity purified $30 \mathrm{kd} A B,(B, E, H, K) P 2 O A B$, and $(C, F, I, L)$ affinity purified $1460 A B$. The dystrophin domains, shown in the lower panel are as reported by Koenig et al. ${ }^{29}$ Arrows indicate dystrophin. (Bar in $L=60 \mu m$ as in all panels.) 
within the sarcoplasma between the distal nuclei and the myotendinous junction. ${ }^{28}$ This distribution was found in the present study for all three antibodies (fig $4 \mathrm{~A}, \mathrm{~B}, \mathrm{C}$, arrows). The proximal $30 \mathrm{kd}$ antibody (AB) clearly stains the same region of the myotubes in all three Duchenne fetuses (fig $4 \mathrm{D}, \mathrm{G}, \mathrm{J}$ ). In contrast, with the P20 antibody, the dystrophin signal was absent from the myotubes of fetus 1 (fig $4 \mathrm{E}$ ), while it was present in fetuses 2 and 3 (fig $4 \mathrm{H}, \mathrm{K}$ ). Finally, none of the three Duchenne fetuses showed any signal with the $\mathrm{COOH}$-terminal antibody 1460 (fig 4 $F, I, L)$. We noted that the muscle tissue of fetus 1 consistently and reproducibly stained very slightly above background with the P20 antibody, although this is difficult to visualise photographically (in fig 4 E). As the P20 antibody spans the region of the gene duplication of this fetus, a small portion of the epitopes should still be detectable. More precise mapping of this duplication mutation has not yet been possible.

\section{Discussion}

By using three different antisera in our immunohistochemical studies of DMD fetal tissue we have shown truncated dystrophins, lacking the $\mathrm{COOH}$ domain supposed to be involved in anchoring the protein with the plasma membrane via glycoproteins. ${ }^{30} 31$ Biochemical studies of Patel $e t a l^{32}$ have also shown traces of dystrophin in some DMD fetuses. Our findings are consistent with the frameshift hypothesis and can be reconciled with the absence of dystrophin in most older DMD patients by concluding that these truncated, unintegrated dystrophins are degraded at a later stage in muscle development. These results independently corroborate a biochemical study, ${ }^{33}$ in which up to $50 \%$ of the younger patients showed truncated dystrophins in their muscle tissue. In principle, some DMD cases could therefore be considered as integration defects rather than synthesis defects. ${ }^{17}$ We should point out that, although some dystrophin antibodies cross react with other proteins present in DMD patients, ${ }^{34}{ }^{35}$ the antibodies used in the present study show no cross reaction in older DMD patients $\left(30 \mathrm{kd},{ }^{34} 1460,{ }^{33}\right.$ and this study for P20 (fig 3) and 1460 (fig 4 F, I, L)), nor in mdx mice. However, we cannot exclude the sharing of antigenic determinants between putative, exclusively embryonic, dystrophin-like proteins with a similar appearance early in embryogenesis. To investigate this further, additional biochemical studies of early fetal muscle would be required. This work has so far been hampered by the considerable dilution of the epitopes at this stage. The finding of different, truncated dystrophins obviously has great diagnostic significance for the $35 \%$ of DMD mutations not detectable by DNA analysis.

The application of these three antibodies allowed us to confine two hitherto undetectable mutations to the distal half of the protein. In the near future, a series of antibodies covering the entire dystrophin could be used to map mutations, which are otherwise undetectable, in a similar way. As well as indicating the position of mutations, this analysis also highlights the at risk haplotype. In family 3 (fig 1) the fetus has apparently inherited the affected haplotype. This raises the carrier risk of the mother to $100 \%$ and directly identifies the at risk haplotype. In a similar way to a biochemical study of Bieber $e t a l^{36}$ carried out at 21 weeks of gestation, dystrophin analysis has settled the issue of carriership of the mother. This raises the question of the confidence with which the other haplotype can now be diagnosed as unaffected in subsequent pregnancies. A retrospective study of muscle material of aborted fetuses at $50 \%$ risk should settle this issue. Hopefully, a thorough regional epitope analysis in DMD/BMD fetuses and BMD patients will lead to a better understanding of the determinants of dystrophin stability. This seems both a rational and an obvious step on the way to therapeutic intervention in the course of this disease.

We thank Myriam van Miert, Willy Geerts, Jacqueline Vermeulen, and Sander Kneppers for expert technical assistance; L M Kunkel and M Koenig for probes; Eric Hoffman for kindly providing sheep antidystrophin; Kenneth Fischbeck for the rabbit anti30 kd antiserum; Maarten D Kloosterman, Jan C Oosterwijk, Dr M Kriek, and Dr F J Los for providing muscle tissue; and Cars Gravemeijer for the photography. This work was supported by the Netherlands Foundation for Medical Research MEDIGON and the Dutch Prevention Fund to GJBvO, the Muscular Dystrophy Association (USA) and the Muscular Dystrophy Group of Great Britain to $\mathrm{GJBvO}$, and the Princes Beatrix Fonds to GJBvO and AFMM.

1 Bakker E, Hofker MH, Goor N, et al. Prenatal diagnosis and carrier detection of Duchenne muscular dystrophy with closely linked RFLPs. Lancet 1985;i:655-8.

2 Bakker E, Bonten EJ, Veenema $\mathrm{H}$, et al. Prenatal diagnosis of Duchenne muscular dystrophy: a three year experience in a rapidly evolving field. F Inher Metab Dis 1989;12(suppl I): $174-90$.

3 Koenig M, Hoffman EP, Bertelson CJ, Monaco AP, Feener C, Kunkel LM. Complete cloning of the Duchenne muscular dystrophy (DMD) cDNA and preliminary genomic organization of the DMD gene in normal and affected individuals. Cell 1987;50:509-17.

4 Koenig M, Beggs AH, Moyer M, et al. The molecular basis for Duchenne versus Becker muscular dystrophy: correlation of severity with type of deletion. Am F Hum Genet 1989;45:498-506.

5 Forrest SM, Cross GS, Thomas NST, et al. Effective strategy for prenatal prediction of Duchenne and Becker muscular dystrophy. Lancet 1987;i:1294-6.

6 Hoffman EP, Brown RH, Kunkel LM. Dystrophin: the protein product of the Duchenne muscular dystrophy locus. Cell 1987;51:919-28.

7 Arahata $\mathrm{K}$, Ishiura S, Ishiguro $\mathrm{T}$, et al. Immunostaining of 
skeletal and cardiac muscle surface membrane with antibody against Duchenne muscular dystrophy peptide. Nature 1988; 333:861-3.

8 Zubrzycka-Gaarn EE, Bulman DE, Karpati G, et al. The Duchenne muscular dystrophy gene product is localized in the sarcolemma of human skeletal muscle fibres. Nature 1988;333: 466-9.

9 Watkins SC, Hoffman EP, Slayter HS, Kunkel LM. Immunoelectron microscopic localization of dystrophin in myofibres. Nature 1988;333:863-6.

10 Bonilla E, Samitt CE, Miranda AF, et al. Duchenne muscular dystrophy: deficiency of dystrophin at the muscle cell surface. Cell 1988;54:447-52.

11 Hoffman EP, Fischbeck KH, Brown RH, et al. Dystrophin characterization in muscle biopsies from Duchenne and Becker muscular dystrophy patients. $N$ Engl f Med 1988;318:1363-8.

12 Malhotra SB, Hart KA, Klamut HJ, et al. Frame-shift deletions in patients with Duchenne and Becker muscular dystrophy. Science 1988;242:755-9.

13 Baumbach LL, Chamberlain JS, Ward PA, Farwell NJ, Caskey CT. Molecular and clinical correlations of deletions leading to Duchenne and Becker muscular dystrophies. Neurology 1989; 39:465-74.

14 den Dunnen JT, Bakker E, van Ommen GJB, Pearson PL. The DMD gene analysed by field inversion gel electrophoresis. $\mathrm{Br}$ Med Bull 1989;45:644-58.

15 Gillard EF, Chamberlain JS, Murphy EG, et al. Molecular and phenotypic analysis of patients with deletions within the deletion-rich region of the Duchenne muscular dystrophy (DMD) gene. Am f Hum Genet 1989;45:507-20.

16 Monaco AP, Bertelson CJ, Liechti-Gallati S, Moser H, Kunkel LM. An explanation for the phenotypic difference between patients bearing partial deletions of the DMD locus. Genomics 1988;2:90-5.

17 Ginjaar IB, Bakker E, den Dunnen JT, et al. Immunological study of dystrophin in Duchenne fetus. Lancet 1989;ii:1212-3.

18 Kunkel LM, Tantravali U, Eisenhard M, Latt SA. Regional localization on the human $\mathrm{X}$ of DNA sequences cloned from flow sorted chromosomes. Nucleic Acids Res 1982;10:1557-61.

19 Hofker MH, Wapenaar MC, Goor N, Bakker E, van Ommen GJB, Pearson PL. Isolation of probes detecting restriction length polymorphisms from X-chromosome specific libraries. Hum Genet 1985;70:148-56.

20 Kunkel LM, Monaco P, Middlesworth W, Ochs HD, Latt SA. Specific cloning of DNA fragments absent from DNA of a male with an X chromosome deletion. Proc Natl Acad Sci USA 1985;82:4778-82.

21 Hofker MH, van Ommen GJB, Bakker E, Burgmeister M, Pearson PL. Development of additional RFLP probes near the locus for Duchenne muscular dystrophy by cosmid cloning of the DXS84(754) locus. Hum Genet 1986;74:270-4.

22 Moorman AFM, Schalekamp MPA, De Boer PAJ, Geerts WJC Lamers WH, Charles R. Immunohistochemical analysis of the distribution of histone $\mathrm{H} 5$ and hemoglobin during chicken development. Differentiation 1987;34:161-7.

23 Moorman AFM, de Boer PAJ, Linders MT, Charles R. The histone H5 variant in Xenopus laevis. Cell Diff 1984;14:113-2.

24 Arahata K, Hoffman EP, Kunkel LM, et al. Dystrophin diagnosis: comparison of dystrophin abnormalities by immunofluorescence and immunoblot analysis. Proc Natl Acad Sci USA 1989;86:7154-8.

25 Wapenaar MC, Kievits T, Hart KA, et al. A deletion hotspot in the Duchenne muscular dystrophy gene. Genomics 1988;2: 101-8.

26 den Dunnen JT, Grootscholten PM, Bakker E, et al. Topography of the DMD gene: Fige- and cDNA analysis of 194 cases reveals 115 deletions and 13 duplications. Am $\mathcal{F}$ Hum Genet 1989;45: $835-47$.

27 Arahata K, Ishihara T, Kamakura K, et al. Mosaic expression of dystrophin in symptomatic carriers of Duchenne's muscular dystrophy. $N$ Engl F Med 1989;320:138-42.

28 Wessels A, Ginjaar IB, Moorman AFM, van Ommen GJB. Different localization of dystrophin in developing and adult human skeletal muscle. Muscle Nerve 1991;14:1-7.

29 Koenig M, Kunkel LM. Detailed analysis of the repeat domain of dystrophin reveals four potential hinge segments that may confer flexibility. F Biol Chem 1990;265:4560-6.

30 Campbell KP, Kahl SD. Association of dystrophin and an integral membrane glycoprotein. Nature 1989;338:259-62.

31 Ervasti JM, Ohlendieck K, Kahl S, Gaver M, Campbell $K$. Deficiency of a glycoprotein component of the dystrophin complex in dystrophic muscle. Nature 1990;345:315-9.

32 Patel K, Voit T, Dunn MJ, Strong PN, Dubowitz V. Dystrophin and nebulin in the muscular dystrophies. $\mathcal{F}$ Neurol Sci 1988;87: 315-26.

33 Bulman DE, Murphy EG, Zubrzycka-Gaarn E, Worton RG, Ray PN. Differentiation of Duchenne and Becker muscular dystrophy phenotypes with amino- and carboxy-terminal antisera specific for dystrophin. Am f Hum Genet 1991;48:295-304.

34 Hoffman EP, Beggs AH, Koenig M, Kunkel LM, Angelini C Cross-reactive protein in Duchenne muscle. Lancet 1989;ii: $1211-2$.

35 Love DR, Hill DF, Dickson G, et al. An autosomal transcript in skeletal muscle with homology to dystrophin. Nature 1989;339. 55-8.

36 Bieber FR, Hoffman E, Amos JA. Dystrophin analysis in Duchenne muscular dystrophy: use in fetal diagnosis and in genetic counseling. Am F Hum Genet 1989;45:362-7. 